ББК 65.428(2Рос)-18

\title{
РЕАЛИЗАЦИЯ ИНТЕГРАЦИОННЫХ ПРОЦЕССОВ В СФЕРЕ ТАМОЖЕННОЙ ПОЛИТИКИ РОССИИ - СУБЪЕКТА ЕАЭС, ПОСРЕДСТВОМ ИНФОРМАЦИОННОГО ОБЕСПЕЧЕНИЯ
}

\author{
(c) 2021 Абашева Екатерина Александровна \\ кандидат юридических наук, доцент кафедры социальных технологий и государственной службы \\ Института экономики и управления \\ Белгородский государственный национальный исследовательский университет, Россия, Белгород \\ E-mail: abasheva229@mail.ru
}

(c) 2021 Колесникова Елена Валентиновна

ассистент кафедры социальных технологий и государственной службы

Института экономики и управления

Белгородский государственный национальный исследовательский университет, Россия, Белгород

E-mail: elena.kolesnickowa@yandex.ru

Разумное ведение дипломатических, экономических отношений, разработка и принятие единого законодательства в области таможенной политики в формате Евразийского экономического союза, безусловно способствуют укреплению и стабилизации международных отношений странучастниц ЕАЭС. Реализуя совместные проекты, получающие закрепление на законодательном уровне, объединенные в Союз государства, обеспечивают защиту в том числе и национальных интересов экономик своих стран. В статье на конкретных примерах, показан «наднациональный» характер правовых норм, регулирующих информационное обеспечение в сфере таможенной политики и представлена их реализация на федеральном уровне российского государства.

Ключевые слова: информационное обеспечение, интеграционные процессы, таможенная политика, евразийская интеграция, наднациональный статус законодательства Евразийского экономического союза.

Современные Евразийские интеграционные процессы базируются не только на исторической, социальной, культурной, этнической общности народов, но и на политической и правовой идентичности. В современном мире, где государственная геополитическая ситуация, оказывающая влияние прежде всего на экономику государств остается весьма нестабильной, огромную роль в вопросах обеспечения геополитической безопасности государств играют информационные ресурсы, в связи с бурным развитием технологий, ставшие одной из движущих сил трансформации глобального информационного общества, реформирования национальных экономик государств, решения актуальных задач как на региональном, так и на международном уровнях.

Таможенная политика Российской Федерации, характеризуется единой концепцией и постепенностью эволюции правовой базы. Внешнеторговая деятельность российского государства подчинена, прежде всего, интересам развития отечественного производства и пополнения государственной казны. Долговременный характер государственных задач, поставленных перед внешнеторговой политикой, предопределил и стабильное развитие законодательной базы российского государства.

Постепенная смена ориентиров в сфере таможенной политики российского государства, привела к необходимости пересмотра основ таможенного законодательства и принципов его содержания, что в свою очередь, требовало системного юридического оформления. Этому процессу способствовали такие объективные факторы в экономическом развитии Российской Федерации, как укрепление национальной промышленности и необходимость интеграции российской экономики и экономических интересов стран ближнего зарубежья, результатом чего стало принятие Таможенного кодекса Евразийского экономического союза (ЕАЭС, Союз) в 2018 году [17].

Таможенная политика, являющаяся одной из 
важнейших частей внешнеторговой деятельности любого суверенного государства и всегда направленная на защиту интересов своей страны на международной арене, безусловно нуждается в информационном обеспечении, которое в России закрепляется на законодательном уровне, о чем свидетельствует Глава 52 «Информационные системы и информационные технологии, используемые таможенными органами» Федерального закона «О таможенном регулировании в Российской Федерации» от 03.08.2018 г. № 289Ф3 [9].

В российском государстве одним из приоритетных направлений выступает информатизация всех сфер государственного управления, являющаяся необходимым атрибутом обеспечения деятельности человека и гражданина, юридических лиц, общественных объединений, государственных структур всех уровней и непосредственно самого государства. Качество, точность и достоверность информации способствуют эффективности и результативности принимаемых решений на государственном уровне.

Понимание информатизации, в качестве процесса способствующего, с помощью перспективных информационных технологий, повышению эффективности применения информации, рациональному использованию информационных ресурсов и реализации многоплановых отношений в сфере государственной политики, позволяет говорить о значимости влияния информатизации на современные интеграционные процессы в сфере таможенной политики российского государства, действующего в интересах своего народа.

Построение и развитие принципов государственной политики информатизации с конца последнего десятилетия XX века в России, содержание которой сводилось к применению информационных технологий и системы информационных ресурсов, нашли свое воплощение в различных программах информатизации. Например, положения, разработанные Федеральной целевой программой «Электронная Россия» (2002-2010 годы)» [10] и Государственной программой «Информационное общество (2011-2020 гг.)» [4] способствовали введению с 2014 года обязательного электронного декларирования.

Заключение 26 февраля 1999 года Договора о Таможенном союзе и Едином экономическом пространстве (между Республиками Беларусь,
Казахстан, Кыргызской Республикой и Российской Федерацией) [3 и создание 29 мая 2014 года Евразийского экономического союза (объединившего в своем составе Россию, Армению, Беларусь, Казахстан, Кыргызскую Республику) [2], целями которых являлась всесторонняя модернизация и кооперация, повышение национальных экономик стран участниц, проведение согласованной и единой политики в экономических отраслях, стало одним из значимых шагов на пути создания новых систем отношений в экономическом секторе стран-участниц экономических конгломераций государств.

Объединение стран в результате заключения Договора о создании ЕАЭС, вступившего в силу на законодательном уровне с 1 января 2015 года и основанного на принципе обеспечения «четыpex свобод», предусматривающих формирование единого рынка товаров, капитала, трудовых ресурсов и услуг, позволило усилить не только интеграционные возможности в экономике государств, заключивших Договор, но и интегрировать общее информационное пространство. В этой связи нельзя не согласиться с мнением автора исследования предпосылок создания и развития Единого информационного пространства ЕАЭС, проведенного К.В.Якушенко отметившим, что сращивание государств в экономическом направлении требует перехода к системе взаимодействия, основанной на использовании информационных потоков и современных цифровых технологий и такая система обусловливает интеграцию информационного и экономического пространства [18, с. 42].

Образование ЕАЭС, безусловно, прежде всего ставит вопрос об экономической интеграции стран-участниц, заключивших Договор, в том числе и такой ее составляющей, как реализация таможенной политики, однако экономическая интеграция, по нашему мнению, подразумевает и интеграцию государств в информационной сфере. В международных отношениях, интеграция выступает одним из способов использования суверенитета стран на региональном уровне, для защиты своих экономических интересов.

В этой связи следует более подробно остановится на рассмотрении значения и роли Евразийской экономической комиссии (ЕЭК, Комиссия), как одной из составляющей реализации информационного обеспечения посредством принятия в пределах своих полномочий решений, носящих нормативно-правовой характер и 
являющихся обязательными для стран, заключивших Договор о ЕАЭС.

Евразийская экономическая комиссия, в структуре ЕАЭС, подчиненная Высшему Евразийскому экономическому совету и обладающая статусом «наднационального» органа управления, создана на основе Договора «О Евразийской экономической комиссии» от 18.11. 2011 г. [1] (утратившим силу 01.01.2015 г. в связи со вступлением в действие Договора о ЕАЭС) и как следствие, принятого в день подписания Договора о ЕАЭС от 29.05.2014 г.- Положения о Евразийской экономической комиссии: Приложение № 1 к Договору о ЕАЭС [15].

Комиссия, выступая в качестве постоянно действующего органа при ЕАЭС, использует вышеупомянутую дефиницию «наднациональный» статус, в двух случаях. Во-первых, когда закрепляется отсутствие наднациональной компетенции Союза при осуществлении координации в сфере внешней торговли услугами (Раздел IX «Внешняя торговля услугами», ст. 38 Договора о ЕАЭС) и во-вторых, когда предполагается принятие государствами-членами ЕАЭС после завершения гармонизации законодательства в сфере финансовых рынков, образование в 2025 г. «наднационального органа» по регулированию финансового рынка, месторасположение которого предполагается в г. Алматы (Переходные положения в отношении Раздела XVI, ст. 103 Договора ЕАЭС). Если в первом случае (ст. 38) нет прямого указания на «наднациональный статус» ЕАЭС, то во втором случае (ст. 103), по нашему мнению, ссылка на «наднациональный» статус Союза усматривается, что подтверждается положением, закрепленным в данной статье «Государства-члены после завершения гармонизации законодательства в сфере финансовых рынков, примут решение о полномочиях и функциях наднационального органа ...» [2].

В пользу обстоятельства, что в деятельности ЕЭК, направленной на определение правил функционирования общего хозяйственного пространства ЕАЭС, просматривается «наднациональный» уровень, говорит и реализация норм Комиссии посредством закрепления ее рекомендаций в национальном законодательстве России в сфере таможенной политики.

В качестве примера можно привести положения Решения Совета ЕЭК от 20.12.2017 г. № 107 раскрывающее отдельные вопросы, связанные с товарами для личного пользования в отношении беспошлинного ввоза, размера пошлин, налогов и многих других вопросов [13], получившие реализацию в Главе 37 Таможенного кодекса ЕАЭС посвященную особенностям порядка и условий перемещения через таможенную границу Союза товаров для личного пользования [17] и в таком национальном нормативно-правовом акте как «О перемещении физическими лицами товаров в сопровождаемом багаже» Письмо Министерства финансов РФ от 17.04.2018 г. № 03-10-03/25651 [8], где закрепляется, что Решением Совета ЕЭК предусмотрено «поэтапное снижение стоимостных и весовых норм, в пределах которых товары для личного пользования (за исключением этилового спирта, алкогольных напитков, пива, неделимых товаров для личного пользования) могут ввозиться беспошлинно. Так, с 1 января по 31 декабря 2019 г.- стоимость не должна быть более 1000 евро, а вес не более 50 кг. С 1 января по 31 декабря 2020 г - стоимость не должна превышать 750 евро, а вес не более 35 кг. С 1 января 2021 г.- стоимость в эквиваленте не более 500 евро, вес не более 25 кг [8]. Однако, физическим лицам, пересекающим таможенную границу ЕАЭС, следует помнить, что если выпускающая сторона допускает определенные нормы вывоза в отношении упомянутой алкогольной продукции, то это не означает, что принимающая сторона может допустить ввоз данной продукции в указанных объемах, поскольку каждое государство, в том числе и в целях защиты национальных интересов, вправе определять индивидуальные нормы объема ввозимой продукции.

Другим фактом, указывающим на «наднациональный» уровень Решений ЕЭК по отношению к национальному законодательству, реализованному Российской Федерацией, посредством принятия соответствующих нормативноправовых актов, является Решение Коллегии ЕЭК от 21.04.2015 г. № 30 «О мерах нетарифного регулирования» Раздел 2.14 «Лекарственные средства» [7], положения которого, хотя и косвенно, получили отражение, например, в Федеральном законе «О государственном контроле (надзоре) и муниципальном контроле в Российской Федерации» от 31.07.2020 г. № 248Ф3 в части «организации и осуществлении федерального государственного контроля (надзора) в сфере обращения лекарственных средств» [5] и претерпевающий актуальные изменения в соответствие с требованиями времени Федеральный закон Российской Федерации «Об обращении 
лекарственных средств» № 61-ФЗ, где в Главе 9 регламентируются ввоз и вывоз лекарственных средств из Российской Федерации [11].

В качестве еще одного аргумента в пользу «наднационального» статуса Решений Евразийской экономической комиссии, можно также привести Решение Коллегии ЕЭК от 02.04.2019 г. № 53 «О классификаторе видов документов, удостоверяющих личность» [6], положения которого реализованы посредством закрепления в ст. 24 п. 3 Приказа Минфина России от 11.09.2020 г. № 190н «Об определении порядка совершения таможенных операций в отношении товаров, пересылаемых в международных почтовых отправлениях в Российской Федерации, в том числе проставления таможенным органом соответствующих отметок, а также порядка и формы представления в таможенный орган информации, используемой при совершении таможенных операций в отношении данных товаров, посредством информационных систем таможенных органов» [12].

Первостепенное значение в качестве нормативно-правового акта, способствующего развитию интеграционных отношений странучастниц ЕАЭС в области формирования единого информационного пространства, носит «Протокол об информационно-коммуникационных технологиях и информационном взаимодействии в рамках Евразийского экономического союза», закрепленный на законодательном уровне в Приложении № 3 к Договору о ЕАЭС, по своей сути представленный различными системами и реестрами [16]. Назначение подобных реестров заключается в содействии упрощения процессом обмена информацией в сфере таможенной политики между государствамичленами ЕАЭС.

В качестве свидетельства реализации на федеральном законодательном уровне России положения вышеназванного документа, а именно ст. 5 «В рамках интегрированной системы формируются общие информационные ресурсы, содержащие ...» п. 3 «реестры, формируемые на основе информационного взаимодействия государств-членов и Комиссии» [16], в частности получили закрепление в ст. 4-6 Приказа Минфина России от 11.09.2020 г. № 190 негулирующим таможенное декларирование товаров для личного пользования, пересылаемых в международных почтовых отправлениях [12].

Ярким примером результативности создан- ных на сегодняшний день специальных баз данных на международном уровне стран-участниц ЕАЭС в части создания реестров, может служить Реестр объектов интеллектуальной собственности (РОИС), изначально, положения которого нашли отражение в Главе 52 «Меры по защите прав на объекты интеллектуальной собственности, принимаемые таможенными органами» ст. 385 (Единый таможенный реестр ...), ст. 386 (Национальные таможенные реестры ...) Таможенного кодекса ЕАЭС от 01.01.2018 г. [17], затем в Главе 57 «Меры по защите прав на объекты интеллектуальной собственности, принимаемые таможенными органами» Федерального закона «О таможенном регулировании в Российской Федерации» от 03.08.2018 г. [9] и Приказе ФТС России от 28.01.2019 г. № 131 «Об утверждении Административного регламента Федеральной таможенной службы по предоставлению государственной услуги по ведению таможенного реестра объектов интеллектуальной собственности» [14].

Все вышеперечисленные факты тщательной проработки на международном и федеральном уровне (приведенного в данной статье на примере российского государства) нормативно-правового регулирования интеграции информационного пространства между государствами-участницами ЕАЭС, свидетельствуют о том, что подобная детализация норм законодательства безусловно способствует не только эффективности механизма защиты национальных интересов российского государства в сфере таможенной политики, но и процессу самой Евразийской интеграции, благодаря которой, исходя из собственных приоритетов, постепенно выстраиваются устойчивые горизонтальные связи между странами Союза, позволяющие достойно выдерживать конкуренцию с другими крупными Союзами, например Европейским союзом.

Как показывает практика, цели и деятельность Евразийского экономического союза, выступающего в качестве сравнительно нового субъекта международных отношений и реализуемые посредством общего медиа-пространства, совместной созидательной работы различных общественных организаций и корпораций государств-участниц ЕАЭС, в первую очередь строятся на согласованности национальных интересов стран Союза, где в качестве базиса Евразийской интеграции в первую очередь выступает законодательство. 


\section{Библиографический список}

1. Договор о Евразийской экономической комиссии от 18.11.2011 г. (утратил силу 01.01.2015) / Онлайнсправочник «Таможенные документы». URL: https://www.alta.ru/tamdoc/11z00000/ (дата обращения: 15.07.2021)

2. Договор о Евразийском экономическом союзе. (Подписан в г. Астане 29.05.2014) (ред. от 01.10.2019 г.) / КонсультантПлюс. URL: http://www.consultant.ru/document/cons_doc_LAW_163855/ (дата обращения: 15.07.2021)

3. Договор о Таможенном союзе и Едином экономическом пространстве. (Подписан в г. Москве 26.02.1999 г.) / КонсультантПлюс. URL: http://www.consultant.ru/document/cons_doc_LAW_31914/ (дата обращения: 15.07.2021)

4. О государственной программе Российской Федерации «Информационное общество (2011-2020 годы): Распоряжение Правительства РФ от 20 октября 2010 г. N 1815-р (утратило силу) / Гарант. URL: https://base. garant.ru/199708/ (дата обращения: 15.07.2021)

5. О государственном контроле (надзоре) и муниципальном контроле в Российской Федерации: Федеральный закон от 31.07.2020 г. № 248-Ф3 (ред. от 11.06.2021) / КонсультантПлюс. URL: http://www.consultant.ru/ document/cons_doc_LAW_358750/(дата обращения: 15.07.2021)

6. О классификаторе видов документов, удостоверяющих личность: Решение Коллегии ЕЭК от 02.04.2019 г. № 53 / Онлайн-справочник «Таможенные документы». URL: https:/www.alta.ru/tamdoc/19kr0053/ (дата обращения 15.07.2021)

7. О мерах нетарифного регулирования: Решение Коллегии ЕЭК от 21.04.2015 г. № 30 (ред. от 20.04.2021) / КонсультантПлюс. URL: http://www.consultant.ru/document/cons_doc_LAW_178556/ (дата обращения: 15.07.2021)

8. О перемещении физическими лицами товаров в сопровождаемом багаже» Письмо Министерства финансов РФ от 17.04.2018 г. № 03-10-03/25651 / Гарант.RU: URL: https://www.garant.ru/products/ipo/prime/ doc/71854108/ (дата обращения: 15.07.2021)

9. О таможенном регулировании в Российской Федерации: Федеральный закон от 03.08.2018 г. № 289-Ф3 (ред. от 20.04.2021) / КонсультантПлюс. URL: http://www.consultant.ru/document/cons_doc_LAW_304093/ (дата обращения: 15.07.2021)

10. О Федеральной целевой программе «Электронная Россия (2002-2010 годы)»: Постановление Правительства РФ от 28.01.2002 г. № 65 (утратило силу) / Гарант. URL: https://base.garant.ru/184120/ (дата обращения: 15.07.2021)

11. Об обращении лекарственных средств: Федеральный закон от 12.04.2010 г. № 61-Ф3 (ред. от 11.06.2021) / КонсультантПлюс. URL: http://www.consultant.ru/document/cons_doc_LAW_99350/ (дата обращения: 15.07.2021)

12. Об определении порядка совершения таможенных операций в отношении товаров, пересылаемых в международных почтовых отправлениях в Российской Федерации, в том числе проставления таможенным органом соответствующих отметок, а также порядка и формы представления в таможенный орган информации, используемой при совершении таможенных операций в отношении данных товаров, посредством информационных систем таможенных органов: Приказ Минфина России от 11.09.2020 г. № 190 н / Онлайн-справочник «Таможенные документы». URL: https:/www.alta.ru/tamdoc/20a00190/ (дата обращения 15.07.2021)

13. Об отдельных вопросах, связанных с товарами для личного пользования: Решение совета ЕЭК от 20.12.2017 г. № 107 (ред. от 11.09.2020) / Онлайн-справочник «Таможенные документы». URL: https://www. alta.ru/tamdoc/17sr0107/ (дата обращения 15.07.2021)

14. Об утверждении Административного регламента Федеральной таможенной службы по предоставлению государственной услуги по ведению таможенного реестра объектов интеллектуальной собственности: Приказ ФТС России от 28.01.2019 г. № 131 / КонсультантПлюс. URL: http://www.consultant.ru/document/cons doc_LAW_326464/b4a46907460ed7f45f557877aad1ffcc1ea8b7d1/\#dst100013 (дата обращения 15.07.2021)

15. Положение о Евразийской экономической комиссии: Приложение № 1 к Договору о Евразийском экономическом союзе от 29.05.2014 г. (ред. от 01.10.2019) / КонсультантПлюс. URL: http://www.consultant.ru/ document/cons_doc_LAW_163855/8e3543f8dc9861d6acfa6a0c6678b972da1d07d0/ (дата обращения: 15.07.2021)

16. Протокол об информационно-коммуникационных технологиях и информационном взаимодействии в рамках Евразийского экономического союза: Приложение № 3 к Договору о ЕАЭС от 29.05.2014 г. (ред. от 01.10.2019) / КонсультантПлюс. URL: http://www.consultant.ru/document/cons_doc_LAW_163855/aa0c4fa9ba6 41f06aаea596cd1596d2c7a7e2107/ (дата обращения 15.07.2021) 
17. Таможенный кодекс Евразийского экономического союза от 01.01.2018 г. (ред. от 29.05.2019) / КонсультантПлюс.- URL: http://www.consultant.ru/document/cons_doc_LAW_215315/ (дата обращения 15.07.2021)

18. Якушенко К.В. Единое информационное пространство Евразийского экономического союза: предпосылки создания и измерение развития // Экономические и социально-гуманитарные исследования. 2019. № 4 (24). С. 42-48. 